\title{
Communication and Power in Collaborative Networks: The Hypothesis of Technology as Confidence Enhancer
}

\author{
Ana Gomes ${ }^{1}$ and Maria Cristina Maneschy ${ }^{2}$ \\ ${ }^{1}$ Socius/ISEG - Universidade Técnica de Lisboa, R. Miguel Lupi, 20, 1249-078, Lisbon, \\ Portugal \\ acalapez@estgp.pt \\ ${ }^{2}$ Universidade Federal do Pará, Campus Universitário do Guamá, R. Augusto Corrêa, 1, \\ CEP 66075-110, Belém, Pará, Brasil \\ cristina@ufpa.br
}

\begin{abstract}
Since the eighties of the $20^{\text {th }}$ century that the social and organizational sciences are interested in networks as organizational configuration and the identification of the dimensions that determine or influence the effectiveness of their performance, their adaptability and resilience. Communication and power are two of these core dimensions, because they strongly influence the degree of trust latent in the network, and trust is the key ingredient of human systems optimization. Very often a third, as neutral perceived party, plays a determinant role in the systematic negotiation process, which is inherent to collaborative networks [10] dynamics. We argue that computer platforms, perceived as a neutral and transparency enhancer device, may play an important role as trust promoter, namely in strong uncertainty avoidance contexts.
\end{abstract}

Keywords: Collaborative networks, cooperation, communication, power, trust.

\section{Introduction}

This paper has as main objective the presentation and discussion of the hypothesis we propose, and which is the basis of our present research agenda, and simultaneously the innovative contribution of our work. We hypothesise the possibility of developing a computer collaborative platform, which may enhance trust in strong uncertainty avoidance contexts, by playing the role of a neutral perceived partner. We base our hypothesis both on theoretical thinking and empirical data collected in previous case studies carried out in different geographical and social contexts, and using different methodologies [1] [2] [3], such as half-structured interviews submitted to thematic content analysis, surveys and social-network analysis. Regardless of methodology and context ${ }^{1}$, the studies highlight some commonalities, such as power centralization, and a coordination and cross-communication deficit. In both the Brazilian $^{2}$ and the

\footnotetext{
${ }^{1}$ The referred studies concern two different geographical and national spaces, namely Portugal and Brazil, and also different activity areas, namely industry, agriculture and fisheries.

${ }^{2}$ http: / / www geert-hofstede.com/hofstede_brazil.shtml
} 
Portuguese $^{3}$ case, we are dealing with high Power Distance ${ }^{4}$ (PDI) and high Uncertainty Avoidance ${ }^{5}$ (UAI) contexts, which condition an environment of potential distrust towards the out-group and simultaneously the attribution of total responsibility to leadership. These in turn reinforces both power centralization and mistrust. An extended report about collaborative networks in the north of Portugal [3] emphasizes precisely the relevance of leadership and the need for collaborative devices which enhance extended information exchange and promote common work. We propose the development of a collaborative technological platform, which shall be designed integrating social and cultural dimensions in order to help institutionalize ${ }^{6}$ leadership, promote wide information sharing and common work. The advantage of using a technological device, not as a substitute of human interaction or human will, but as a support mechanism, lies on two aspects: first, the speed and extent of sharing possibilities, and second and perhaps even more important, technology tends to be socially perceived as a neutral player, which means that people frequently consider that technological devices have no will of their own and therefore no hidden agenda. As perceived neutral players they may contribute to build up confidence inside the system, for instance promoting the social rewarding of cooperative attitudes and action through game like devices.

In short, we may consider as innovative contributions of our proposition the intentional integration of context bond social and cultural dimensions in the design of a collaborative platform and the deliberate use of its neutrality perception as network confidence enhancer.

\section{A Collaboration Unfriendly Context}

It is broadly consensual that during the last two decades of the $20^{\text {th }}$ century the conditions for a deep transformation of organizational structures emerged. During the 80's the extension and strengthening of global competition and its immediate consequences, generated a significant pressure on production costs which dictated the need for radical rationalization [4] and innovation [5], [6], namely process innovation [7]. During the 90's the massive proliferation of ICT use inevitably imposed the need to perform in network organised teams [8] [9] [10]. If on the one hand, this kind of organization has become an imperative, on the other hand, it puts the problem of the need for cooperation, which is not an evident issue [11] [3]. Its quality depends

\footnotetext{
${ }^{3}$ http: / / www.geert-hofstede.com/hofstede_portugal.shtml

${ }^{4}$ As defined by Hofstede, the Power Distance Index (PDI) shows "the extent to which the less powerful members of organizations and institutions (like the family) accept and expect that power is distributed unequally. This represents inequality (more versus less), but defined from below, not from above. It suggests that a society's level of inequality is endorsed by the followers as much as by the leaders" [12]

5 As defined by Hofstede, the Uncertainty Avoidance Index (UAI) "deals with a society's tolerance for uncertainty and ambiguity; it ultimately refers (...) to what extent a culture programs its members to feel either uncomfortable or comfortable in unstructured situations. Unstructured situations are novel, unknown, surprising, different from usual. Uncertainty avoiding cultures try to minimize the possibility of such situations". [12]

${ }^{6}$ Decentralize across the organizational network.
} 
largely on contextual dimensions, namely the degree of perceived insecurity, and how the involved actors deal with it.

Regardless of the context, it is clear that the network organizational form increases the insecurity of social relations in that it broadens the range of potential and effective interactions and destroys the security of traditional organisational borders. But the way in which this insecurity is perceived and dealt with is contextual bond. In contexts where high PDI and UAI coexist [12], like in Brazil and Portugal collaboration became a very difficult exercise.

Collaboration involves necessarily a high level of communication, which itself implies the act of making something in common and accordingly there must be a certain degree of trust. We may define trust as the social belief about the predictability of actions [13], or the suspension of doubt [14]. In the absence of trust, Uncertainty Avoidance increases. The combination of high PDI and high UAI scores results in bad quality ${ }^{7}$, mostly downward vertical communication. Horizontal communication is generally almost exclusively informal, based on personal affective ties [15], and as such contingent and risky [16]. Simultaneously, the very relationship with power is ambiguous and contradictory, since ties with power holders are of course sought, but simultaneously suspicion loaded. The difference between personalised and socialised power [17] is hardly perceived, and personal power is mostly regarded as free of any activity inhibition (self-control) [17], so that leaders are perceived to act exclusively motivated by self-interest, not hesitating to sacrifice in the process the interests of the larger community. This situation configures a paradox insofar as the social need for security leads to the acceptance of power and responsibility transfer to the person of a leader, but the leader itself is mistrusted. The centralization of power also implies the concentration of information access, if only because it diminishes and devalues horizontal communication.

A network of organizations involves continuous negotiation and therefore implies the existence of mediating factors, in order to keep conflict in manageable levels. A mediator, by definition, must be perceived as a neutral part of the game. Our hypothesis is that collaborative computer interfaces may play the role of the perceived neutral part, not so much as conflict mediator, but as conflict preventer, in that it may contribute for the improvement of communication quality, through higher transparency and the fulfilling of an "automatic" role of social control, which rewards and punishes behaviours, namely cooperative and non-cooperative behaviours.

\section{Empirical Evidence}

Two empirical studies relating to networks of rural producers were conducted, in very different environments (Portugal and Brazilian Amazonia), using different methodologies (half-structured interviews and social network analysis respectively), and both reveal high power distance, preponderance of vertical communication, mistrust and occasional extension of the network based on personal and family relations without any apparent middle or long-term strategic thinking [2] [1].

${ }^{7}$ Scarce, ambiguous and often redundant and inadequate communication, which does not transmit the effectively needed information. 


\subsection{Rural Associations in the Amazonia}

In 2005 a preliminary study was undertaken about the rural associations in the northeast of Pará State, Brazilian Amazonia [2]. External pressures for associating, namely public development programs, technical assistance, access to land and training possibilities stimulated the formation of peasant associations [18] [19]. Overall, the emergence of these local associations has been linked to concerns about popular participation and decentralization of state functions [20]. The analysis of the characteristics of the networks of associations was carried out using Ucinet and Netdraw, [21].

Here are briefly presented the main features of the networks of the 36 associations studied. Their contacts comprised other similar associations, social groups, individuals, organizations and public institutions. The main nodes, those exhibiting more links, are banks and the technical and funding assistance agency.

Most of the fishermen and farmers associations' contacts tended to be homogeneous and more geographically limited. Their main contacts were: firstly, the banks and the above referred agency and, secondly, the politicians. Some central associations, located in more dynamic areas of the municipalities featured numerous and different links, while the majority had relatively few and homogeneous contacts and lacked alternative information sources in the network. The local associations appeared to be linked primarily through common links, i.e., indirectly rather than directly, especially via the unions, the bank, and a few government agencies and NGOs. Fieldwork found that associations in different municipalities were not interacting in a manner that allowed sharing concerns and ways of dealing with them. The structure of contacts reflected these limits. The same applied to the limited exchange of experiences of income generation that some of the local groups were implementing. A thicker and more varied horizontal contact structure would be expected to contribute to influence the agenda of the powerful nodes, notably decision-making institutions and the unions.

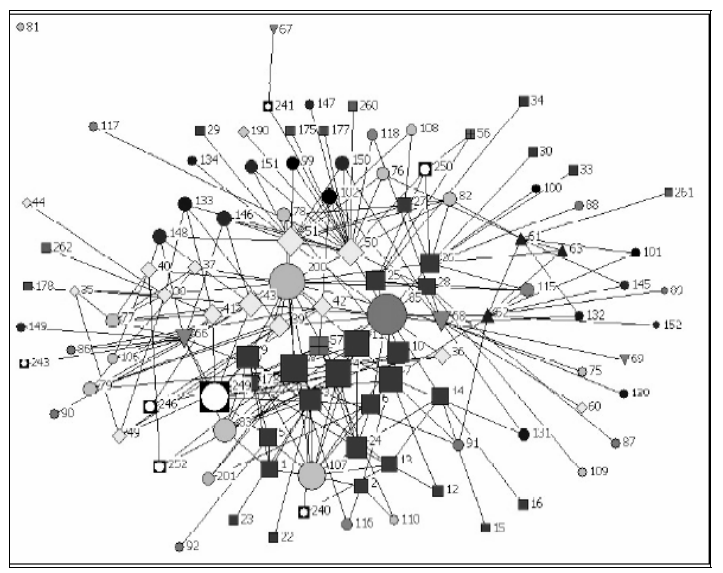

Fig. 1. Exploratory graphic representation of the social relations network involving 36 rural associations in the Pará State. Brazilian Amazonia. Source: [2] 


\subsection{The "Rocha Do Oeste" Network}

In 2008 a network of Portuguese rural producers was studied using qualitative methodologies, namely half-structured interviews and thematic content analysis [1]. Like in the Brazilian case, the constitution of the producers associations were externally induced by public and supra-national organizations, like the EU. The associative organizational mode was imposed as a form of accessing project funding. The case analyzed concerns the cultivation and commercial distribution of the "Rocha do Oeste" pear, and its transformation in a kind of "identity product" [22]. The network has proven to be very effective with regard to the quantitative growth of the production area as well as a significant improvement of the organoleptic quality of the fruit, but failed in the aim of turning it into an" identity product". Some of the main reasons for this partial failure where diagnosed, and are here presented using passages from the direct discourse of some local social players. The detected problems relate precisely to high power distance ${ }^{8}$, which prevents communication, namely horizontal communication; generalized mistrust ${ }^{9}$, which prevented the consolidation of a common trademark, and lack of strategic thinking ${ }^{10}$, which

\section{General latent mistrust}

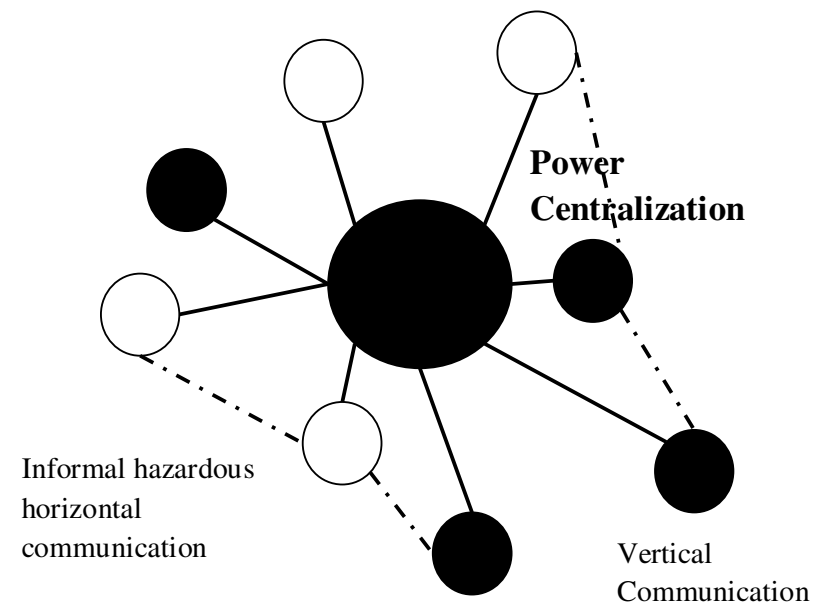

Fig. 2. Network cooperation ineffectiveness dimensions

\footnotetext{
${ }^{8}$ No. They command. They prescribe the treatments we pour in... Everything is done according to their orders. That's all, according to their command. They give the orders. The technicians command us, they tell us what to do. So, it must be precisely as they tell us. (Excerpt of farmer's discourse).

9 The elite is much more involved in their own projects than with the region. The elite are usually inclined to politics and unfortunately politics degenerate into district perspectives which cut the region into pieces. (Excerpt of a local development's agent discourse).

${ }^{10}$ The Oeste, historically this region is based on a casaleiro logic. The casaleiro...he has a little cottage and he imitates his neighbour's cottage. And he does everything alone. His property has no size of a farm. (Excerpt of a local development's agent discourse)
} 


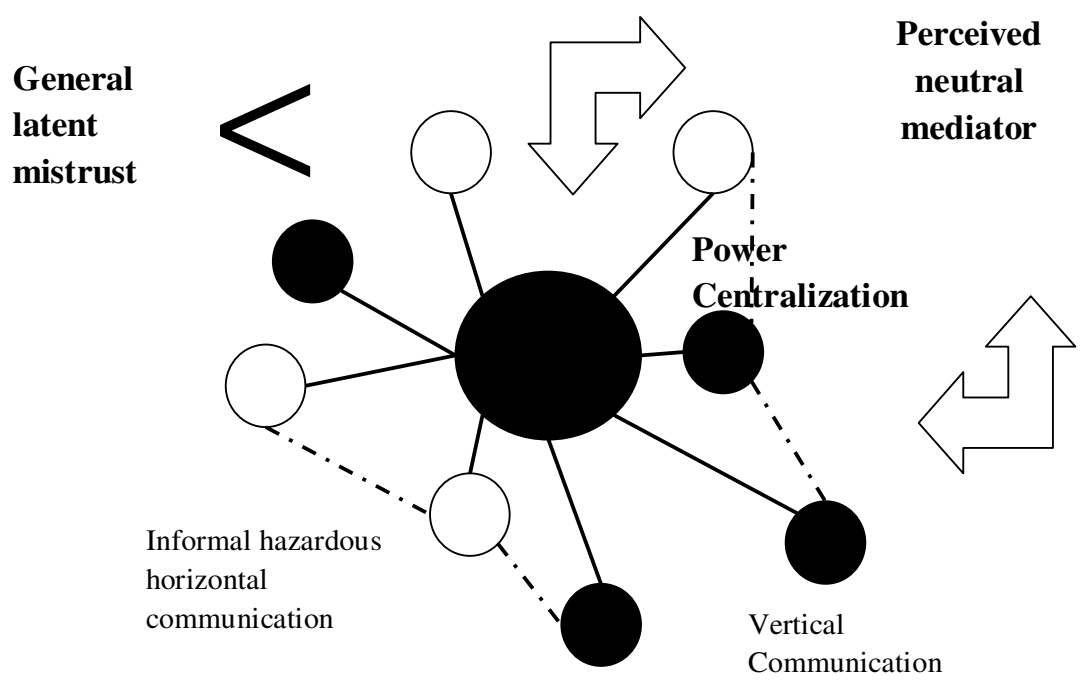

Fig. 3. The hypothesis of the perceived neutral mediator

prevented the diversification of economic and cultural activities around agricultural production $^{11}$. Moreover it also prevented the extension and strengthening of the network in all domains, inclusive the financial, thus perpetuating the dependence upon the original funding institutions ${ }^{12}$.

The high complexity of interrelated factors and dimensions present in both the explained cases may be graphically simplified, in order to abstract the general lines of network structuring of former "isolated" entities. The schemes (Figure 2 and 3) introduce the main ineffectiveness and suggest process improvement possibilities, namely recurring to collaborative software devices.

\section{Discussion and Conclusion}

Considering the fact that technology is often perceived as a neutral factor, we hypothesize that the building of a collaborative computer platform, which takes in account socio-cultural and political dimensions in its development, could contribute to enhance the quality of communication, and therefore the effectiveness of cooperation. Its building requires interdisciplinary effort, flexibility and mutual learning and

${ }^{11}$ I don't know, I really don't know. There's a cook or a craftswoman, I don't know if you'd call her a cook or craftswoman and her name's ...if I'm not mistaken...Zira. Isn't it? Who also...who also makes some products using pears. I don't know her....but I think there's already been some cooperation with her here. A long time ago....(Excerpt of the discourse of producer's association coordinator revealing ignorance about network members).

12 Due to political issues, the Community Support Framework which should have started in January 2007, along with brute disorganisation, the fact is that not a single item of the new community support framework has yet been spent.. Not a single project has been approved. (Excerpt of the discourse of the main producer's association general coordinator). 
monitoring processes. The latter are especially relevant in very heterogeneous networks in order to capitalize the diverse nodes' resources, notably knowledge, skills and experiences. In a context of high UAI and PDI the platform might routinely record and track the members' activities and contacts related to the network objectives and values; moreover, it may produce periodical graph representation of the ties, indicating centrality, density areas and accessibility to embedded resources. Such information might translate into objective assessment criteria, quantitative and qualitative ones. Also, the framing of rewards and sanctions perceived as fair due to the perceived neutrality of the "controller". Expected consequences are: (a) communication transparency able to counteract the historical paradox of leader centrality and mistrust; (b) growing awareness of the balance between constraints and opportunities from membership to the network; (c) more trust based relations between peripheral and central nodes; (d) higher density of the links at lower costs of nurturing them, costs partly covered by the platform data; (e) stimuli for structural and behavioural adjustments; (f) network adaptability to changing environments via real time information and assessment devices.

Such functionalities do not replace consensus-building occasions. They also do not replace strategies oriented to the institutionalization of group relations [23], such as meetings, ceremonies, and rituals.iThe platform is a step towards the participatory management of collaborative networks; its inputs should encourage the mutual recognition of members, their shared concerns and resources, as well as the value of their collaborative actions. Well-informed agents about the network utility and outcomes are supposedly more committed to its rules and success.

\section{References}

1. Gomes, A.: The "Rocha do Oeste": the bourgeoning of a regional identity in the shade of pear orchards. In: Ghent: Proceedings of the 8th European Social Science History Conference (2010),

http: / / www2.iisg.nl/esshc/programme. asp? selyear $=10$ \&

2. Maneschy, M., Klovdahl, A.: Redes de associações de grupos de camponeses na Amazônia Oriental (Brasil): fontes de capital social? Redes - Revista hispana para el análisis de redes sociales 12(4) (2007)

3. Carneiro, L., Soares, A.L., Patrício, R., Alves, A., Madureira, R., Sousa, J.P.: Redes Colaborativas de Elevado Desempenho no Norte de Portugal. INESC, Porto (2007)

4. Hammer, M., Champy, J.: Reenginiering the corporation: a manifesto for business revolution. Harper Business, New York (1993)

5. Freeman, C.: The economics of business innovation. Frances Pinter, London (1982)

6. Drucker, P.: Innovation and entrepreneurship. Elsevier, Burlington (1985)

7. Hammer, M.: Deep change: how operational innovation can transform your company. Harvard Business Review 82(4), 84-93 (2004)

8. Castells, M.: A galáxia Internet: reflexões sobre, Internet, negócios e sociedade. Fundação Calouste Gulbenkian, Lisboa (2004)

9. Castells, M.: A sociedade em rede: a era da informação, economia, sociedade e cultura. Paz e Terra, São Paulo (1999)

10. Camarinha-Matos, L.M., Afsarmanesh, H.: Collaborative Networks: a new scientific discipline. Journal of Intelligent Manufacturing 16, 439-452 (2005) 
11. Rosas, J., Camarinha-Matos, L.M.: An approach to assess collaboration readiness. International Journal of Production Research 47(17), 4711-4735 (2009)

12. Hofstede, G.: Culture's consequences: Comparing Values, Behaviors, Institutions, and Organizations Across Nations. Sage, Thousend Oaks (2001)

13. Fukuyama, F.: Trust. Penguin, London (1995)

14. Möllering, G.: Rational, institutional and active trust:just do it!?, http: / / www.mpifg.de/people/gm/downloads/Moellering_CH2inBijls ma2005_Elgar.pdf

15. Gomes, A.C., Lopes, C.B.: Comunicação e eficácia numa equipa virtua. In: Gomes, A.C., Gonçalves, I.L., Maneschy, M.C. (eds.) Dos dois lados do Atlântico: trabalhadores, organizações e sociabilidades, UFPA/ Paka Tatu, Belém, Pará (2011)

16. Luhmann, N.: Trust and power. Wiley, Chichester (1979)

17. Mc Clelland, D.C.: Power: the inner experience. Irvington, New York (1975)

18. Moreira, E.: Mouvement social pour la défense d'un territoire traditionnel à Porto de Moz (Amazonie Brésilienne): une participation "par le bas". In: Teisserenc, P. (ed.) La mobilisation des acteurs dans l'action publique locale: au Brésil, en France et en Tunisie, pp. 59-72. L'Harmattan, Paris (2006)

19. Hébette, J.: Participation municipale en milieu rural dans l'Etat du Pará: ouverture institutionnelle et contraintes sociopolitiques. In: Teisserenc, P. (ed.) La mobilisation des acteurs dans l'action publique locale: au Brésil, en France et en Tunisie, pp. 33-48. L'Harmattan, Paris (2006)

20. Szreter, S., Woolcock, M.: Health by association? Social capital, social theory and the political economy of public health. International Journal of Epidemiology 33, 650-667 (2004)

21. Borgatti, S., Everett, M., Freeman, L.: Ucinet for Windows: software for Social Network Analysis. Analytic Technologies, Harvard (2002)

22. Pesteil, P.: Au carrefour de l'économique et du culturel: la filière castanéicole corse comme marqueur de l'identité. Études Rurales 157-158, 221-228 (2001)

23. Portes, A.: Social Capital: Its Origins and Applications in Modern Sociology. Annual Review of Sociology 24, 1-24 (1998) 